\title{
Allogeneic haematopoietic stem cell transplantation for advanced stage mycosis fungoides and Sézary syndrome: never-late, never- never?
}

\author{
H. Miles Prince $\mathbb{D}^{1,2,3} \cdot$ Chathuri Abeyakoon ${ }^{1}$
}

Received: 15 October 2020 / Revised: 26 October 2020 / Accepted: 10 November 2020 / Published online: 1 February 2021

(c) The Author(s), under exclusive licence to Springer Nature Limited 2021

Mycosis fungoides (MF) and Sézary syndrome (SS) constitute the majority of primary cutaneous T-cell lymphomas accounting up to $80 \%$ of cases with a median age at diagnosis of 55-60 years. Inherently variable in their clinical behaviour, MF/SS are generally considered incurable. Early-stage disease involves skin patches and plaques (stage I-IIA) and generally has an indolent clinical course with excellent long-term survival rates. Conversely, advancedstage disease (stage IIB-IV) which involves tumours, erythroderma or significant blood, nodal or visceral involvement, carries a poor prognosis with a median survival ranging from 2 to 5 years $[1,2]$.

For patients with advanced-stage disease and in patients with refractory early-stage disease, there are a multitude of therapeutic challenges. Clinicians are constantly faced with lack of effective therapies which have low response rates, short remissions of typically less than 6 months, requiring multiple successive lines of therapy [3]. More recently, targeted therapies such as the antibody drug conjugate brentuximab vedotin for patients with CD30 positive disease and the antibody to CCR4 mogamulizumab have emerged as promising agents $[4,5]$. However, unlike in many other lymphomas, despite these advances, no conventional therapy is curative for advanced-stage MF/SS. Indeed, for those patients of suitable age (unfortunately only $\sim 50 \%$ of patients eligible given the average age of presentation) and performance status and with an identifiable

H. Miles Prince

miles.prince@petermac.org

Epworth HealthCare, Melbourne, 3002 Victoria, Australia

2 Peter MacCallum Cancer Centre, Melbourne, 3000 Victoria, Australia

3 Sir Peter MacCallum Department of Oncology, University of Melbourne, Melbourne, 3000 Victoria, Australia donor, allogeneic hematopoietic stem cell transplantation (alloSCT) remains the only potential curative option and has been clearly demonstrated to achieve a cure in selected patients. To date, the body of evidence is limited to retrospective single centre studies, registry data and small prospective studies with no randomised controlled trials.

In this issue of Bone Marrow Transplantation, Domingo-Domenech et al. present an important update of the outcomes of European Society for Blood and Marrow Transplantation (EBMT) alloSCT registry for advancedstage MF/SS. This analysis included 113 patients and is an extended series of the previously reported outcomes of 60 cases published in 2010, along with an extended follow-up reported in 2014 [6, 7]. Primary endpoints revealed a 5-year predicted median progression free survival (PFS) of $26 \%$ (95\% CI 19-36\%) and an overall survival (OS) of $38 \%$ (95\% CI 30-49\%), respectively. This study represents one of two large patient cohorts with the longest follow-up of surviving patients and complements the large study from the Centre for International Bone Marrow Transplantation Research (CIBMTR) published in 2014, both demonstrating a durable response with alloSCT; the CIBMTR study included 129 patients with MF/SS revealing a 5-year predicted PFS of $17 \%$ (95\% CI 9-26\%) and an OS of 32\% (95\% CI 22-44\%) [8].

Moreover, a recent meta-analysis by Iqbal et al., which included a total of 266 patients from five studies, revealed an attractive pooled OS of 59\% (95\% CI 50-69\%) but a PFS of only $36 \%$ (95\% CI 27-45\%), highlighting the increased risk of disease relapse post alloSCT [9]. Indeed, in this meta-analysis $47 \%$ (95\% CI 41-53\%) relapsed/progressed following alloSCT which was comparable to the 5year relapse/progression in the EBMT study of $45 \%$ (95\% CI $35-54 \%$ ).

The apparent plateau in the survival curve beyond two years as observed in this analysis provides further support that alloSCT can achieve a cure for some patients with 
MF/SS. The analysis also provides some insight into which patients are most likely to benefit. One predictor was undertaking alloSCT earlier in the disease course. Indeed, the superior outcome for those with early-phase (not to be confused with early stage) disease (early-phase defined as complete response 1 or 2 , partial response 1 or 2 or relapse/progression in patients that had received less than three systemic therapies) was similar to the data reported by Cudillo et al. [10]. Conversely, advancedphase (not stage) disease (advanced-phase defined as complete remission/partial remission $>3$, primary refractory or relapse/progression in patients that had received three or more lines of systemic therapy prior to transplant or the number of treatment line not known) at time of transplantation was a negative prognostic factor for both PFS and OS. Others have demonstrated the importance of disease status at time of transplantation as an important prognostic factor [11].

This study also reveals the changes in transplantation management and selection over time; there was a trend to offer alloSCT earlier in the disease course, to an older patient cohort (median age 53-years in the more recent cohort versus a median age of 46-years in the initial cohort) as well as the use of more unrelated donors and T-cell depletion. Despite management improvements over time, the reported non-relapse mortality was a substantial $28 \%$ (95\% CI 20-37\%). The authors did raise concern of the use of unrelated donors, which was an independent negative prognostic factor for OS.

Although this is a valuable paper, there are a few limitations that warrant highlighting. Importantly, this study did not address the impact of disease type on outcome-namely SS versus MF. A number of recent studies from large centres have consistently reported improved outcomes with alloSCT for SS compared with advanced-stage MF. These include the MD Anderson Cancer Centre data which confirmed a 4-year PFS of only $11.4 \%$ in MF and a favourable $73 \%$ in SS $(P=0.04)$. In addition, the 2019 update of the Milan experience, presented in abstract form at the World Congress of Cutaneous Lymphoma in Barcelona 2020, demonstrated a 5year disease free survival of $27.5 \%$ (95\% CI $11-14 \%$ ) for MF and $56 \%$ (95\% CI 32-81\%) for SS, respectively $[12,13]$. Indeed, more research into the differential benefit of alloSCT for SS versus tumour-stage/plaquestage $\mathrm{MF}$ is required.

This EBMT data strengthens the current evidence that alloSCT can achieve cures for patients with MF and SS. Moreover, it emphasises the importance of not delaying alloSCT too long. This may seem a simple recommendation, however clinicians now have available to them exciting new novel agents such as brentuximab vedotin and mogamulizumab which in themselves can impact on survival. Do we delay transplant to make way for these new treatments or do we skip these new agents and move early to transplant? Or use these agents to induce remissions as a bridge to transplant? Such conundrums are not unique to MF/SS and need addressing.

\section{Compliance with ethical standards}

Conflict of interest The authors declare that they have no conflict of interest.

Publisher's note Springer Nature remains neutral with regard to jurisdictional claims in published maps and institutional affiliations.

\section{References}

1. Willemze R, Cerroni L, Kempf W, Berti E, Facchetti F, Swerdlow $\mathrm{SH}$, et al. The 2018 update of the WHO-EORTC classification for primary cutaneous lymphomas. Blood. 2019;133:1703-14. https://doi.org/10.1182/blood-2018-11-881268

2. Imam MH, Shenoy PJ, Flowers CR, Phillips A, Lechowicz MJ. Incidence and survival patterns of cutaneous T-cell lymphomas in the United States. Leuk Lymphoma. 2013;54:752-9. https://doi. org/10.3109/10428194.2012.729831

3. Photiou L, van der Weyden C, McCormack C, Miles Prince H. Systemic treatment options for advanced-stage mycosis fungoides and Sézary syndrome. Curr Oncol Rep. 2018. https://doi.org/10. 1007/s11912-018-0678-x

4. Prince HM, Kim YH, Horwitz S, Dummer R, Scarisbrick J, Quaglino P, et al. Brentuximab vedotin or physician's choice in CD30-positive cutaneous T-cell lymphoma (ALCANZA): an international, open-label, randomised, phase 3, multicentre trial. Lancet. 2017;390:555-66. https://doi.org/10.1016/S0140-6736 (17) $31266-7$

5. Kim YH, Bagot M, Pinter-Brown L, Rook AH, Porcu P, Horwitz SM, et al. Mogamulizumab versus vorinostat in previously treated cutaneous T-cell lymphoma (MAVORIC): an international, open-label, randomised, controlled phase 3 trial. Lancet Oncol. 2018;19:1192-204. https://doi.org/10.1016/S1470-2045 (18)30379-6

6. Duarte RF, Canals C, Onida F, Gabriel IH, Arranz R, Arcese W, et al. Allogeneic hematopoietic cell transplantation for patients with mycosis fungoides and Sézary syndrome: a retrospective analysis of the lymphoma working party of the European group for blood and marrow transplantation. J Clin Oncol. 2010;28:4492-9. https://doi.org/10.1200/JCO.2010.29.3241

7. Duarte RF, Boumendil A, Onida F, Gabriel I, Arranz R, Arcese $\mathrm{W}$, et al. Long-term outcome of allogeneic hematopoietic cell transplantation for patients with mycosis fungoides and Sézary syndrome: a European society for blood and marrow transplantation lymphoma working party extended analysis. J Clin Oncol. 2014;3347-8. https://doi.org/10.1200/JCO.2014.57. 5597

8. Lechowicz MJ, Lazarus HM, Carreras J, Laport GG, Cutler CS, Wiernik PH, et al. Allogeneic hematopoietic cell transplantation for mycosis fungoides and Sezary syndrome. Bone Marrow Transpl. 2014;49:1360-5. https://doi.org/10.1038/bmt.2014.161

9. Iqbal M, Reljic T, Ayala E, Sher T, Murthy H, Roy V, et al. Efficacy of allogeneic hematopoietic cell transplantation in cutaneous $\mathrm{T}$ cell lymphoma: results of a systematic review and metaanalysis. Biol Blood Marrow Transplant. 2020;26:76-82. https:// doi.org/10.1016/j.bbmt.2019.08.019 
10. Cudillo L, Cerretti R, Picardi A, Mariotti B, De Angelis G, Cantonetti M, et al. Allogeneic hematopoietic stem cell transplantation in primary cutaneous T cell lymphoma. Ann Hematol. 2018;97:1041-8. https://doi.org/10.1007/s00277-018-3275-Z

11. de Masson A, Beylot-Barry M, Bouaziz JD, de Latour RP, Aubin F, Garciaz S, et al. Allogeneic stem cell transplantation for advanced cutaneous T-cell lymphomas: a study from the French society of bone marrow transplantation and French study group on cutaneous lymphomas. Haematologica. 2014;99:527-34. https:// doi.org/10.3324/haematol.2013.098145
12. Hosing C, Bassett R, Dabaja B, Talpur R, Alousi A, Ciurea S, et al. Allogeneic stem-cell transplantation in patients with cutaneous lymphoma: updated results from a single institution. Ann Oncol. 2015;26:2490-5. https://doi.org/10.1093/annonc/mdv473

13. Onida F, Vall V, Saporiti G, Alberti-Violett S, Grifoni F, Goldaniga $\mathrm{M}$, et al. Allogeneic hematopoietic stem cell transplantation as a curative treatment strategy for patients with advanced stage mycosis fungoides and Sezary syndrome: 2019 Update of the Milan Experience; World Congress of Cutanoeous Lymphoma: Barcelona. 2020. 